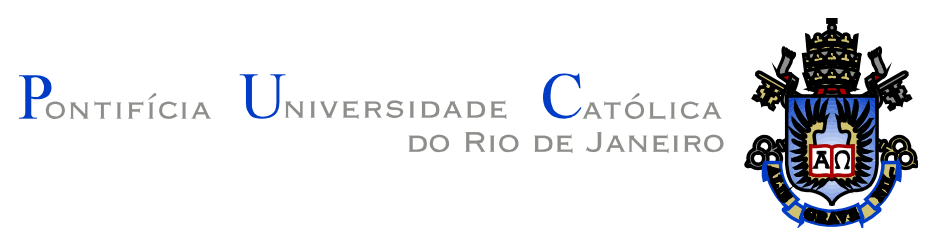

Helmut Isaac Padilla Chavarría

\author{
Dinâmica Molecular da Interação de Dibenzo \\ [a,h]antraceno e de seu Metabólito com Modelos \\ de Membrana Celular e Surfactante Pulmonar
}

Dissertação de Mestrado

Dissertação apresentada como requisito parcial para obtenção do título de Mestre pelo Programa de PósGraduação em Química da PUC-Rio.

Orientador: Prof. André Silva Pimentel

Rio de Janeiro

Agosto de 2014 


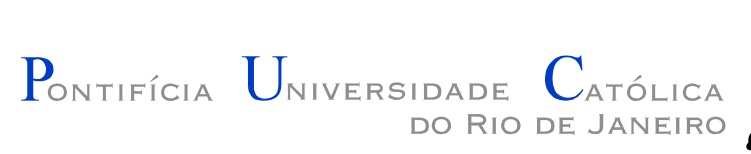

Helmut Isaac Padilla Chavarría

\title{
Dinâmica Molecular da Interação de Dibenzo [a,h]antraceno e de seu Metabólito com Modelos de Membrana Celular e Surfactante Pulmonar.
}

Dissertação apresentada como requisito parcial para obtenção do título de Mestre pelo Programa de PósGraduação em Química da PUC-Rio. Aprovada pela Comissão Examinadora abaixo assinada.

\author{
Prof. André Silva Pimentel \\ Orientador \\ Departamento de QUÍMICA - PUC-Rio \\ Prof. Ernesto Raul Caffarena \\ FIOCRUZ
}

Prof. Adriano Mesquita Alencar USP

Prof. José Eugenio Leal Coordenador Setorial do Centro Técnico Científico - PUC-Rio 
Todos os direitos reservados. É proibida a reprodução total ou parcial sem a autorização da universidade, do autor e do orientador.

\section{Helmut Isaac Padilla Chavarría}

Graduou-se em Engenharia Química Industrial na Universidade Nacional Autónoma de Honduras (UNAH) em 2011.

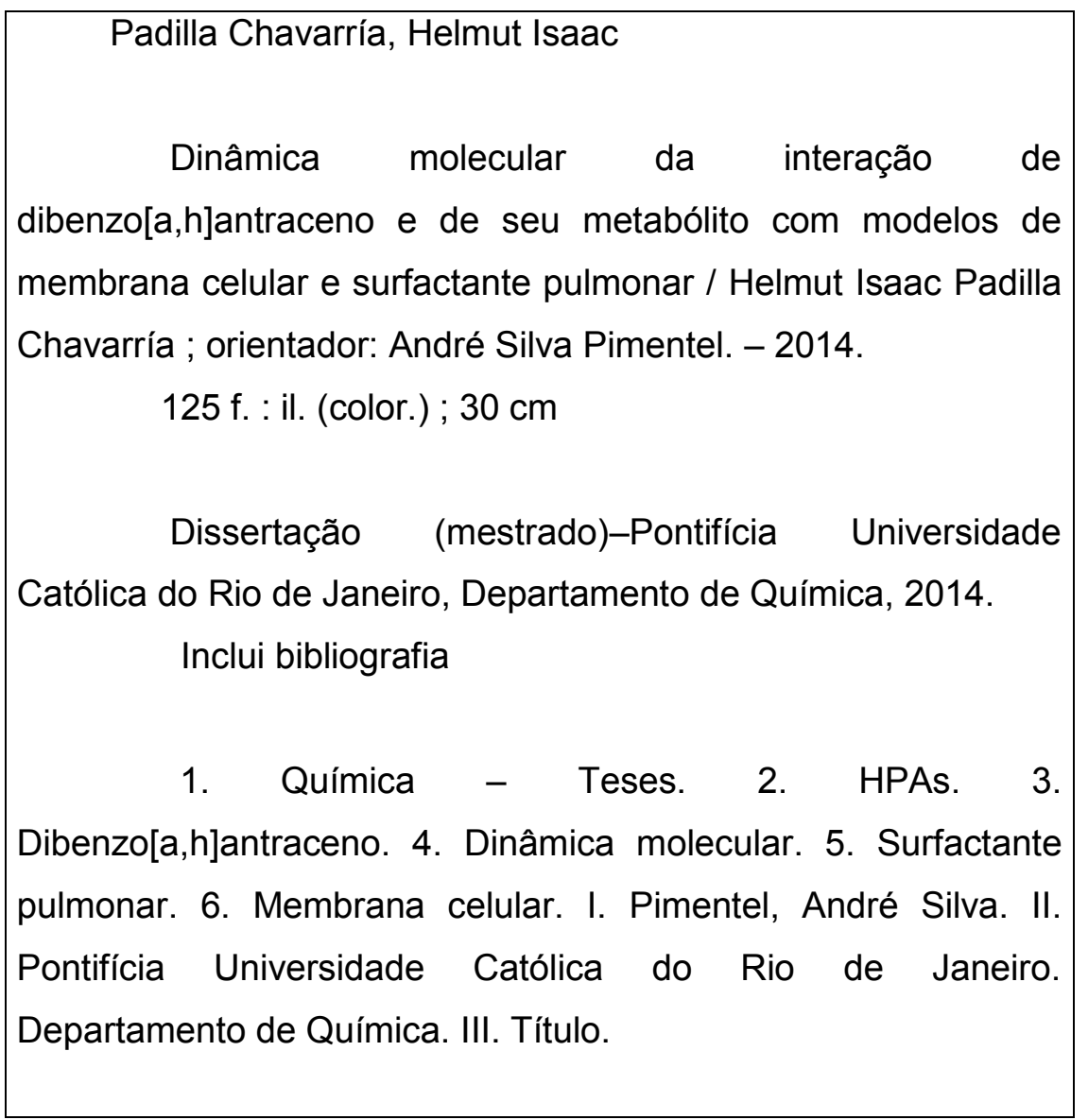

CDD: 540 
Dedico esta dissertação a minha família e amigos, sem eles não seria possível. 


\section{Agradecimentos}

A meu orientador André Silva Pimentel pela confiança e paciência para realizar este trabalho.

A Teobaldo Cuya pela introdução ao mundo da dinâmica molecular e da pesquisa no Brasil.

A CNPq e PUC-Rio pelo fomento concedido para desenvolver este trabalho.

À secretária Fátima Almeida pela facilidade com que resolve os problemas administrativos.

A Ítalo, Mariane, Erika e Alline pelo tempo agradável no laboratório

Aos professores pelo conhecimento que adquiri.

A Josué Molina por me trazer à PUC-Rio e pelas inumeráveis conversas

A Maciel, Jairo, Valto e Zé Roberto por me fazer sentir em casa no Rio de Janeiro.

E finalmente a minha família pelo apoio incondicional. 


\section{Resumo}

Padilla-Chavarría, Helmut Isaac; Pimentel, André Silva. Dinâmica Molecular da Interação de dibenzo[a,h]antraceno e de seu Metabólito com Modelos de Membrana Celular e Surfactante Pulmonar. Rio de Janeiro, 2014. 125p. Dissertação de Mestrado - Departamento de Química, Pontifícia Universidade Católica do Rio de Janeiro.

O estudo da interação de dibenzo[a,h]antraceno (DBahA) e de seu metabólito com modelos de membrana celular e surfactante pulmonar foi realizado através de dinâmica molecular. Os modelos de membrana celular e de surfactante pulmonar são geralmente misturas de dipalmitoil fosfatidilcolina (DPPC), dipalmitoil fosfatidilglicerol (DPPG), e colesterol. No caso do modelo de surfactante pulmonar pode ser incluido as proteínas surfactantes (SP-A, SP-B, SP-C e SP-D). Neste projeto, o dibenzo[a,h]antraceno (DBahA) foi simulado com o DPPC sozinho e com uma mistura 32/32/1 de DPPC/DPPG/Colesterol. DBahA é encontrado nos gases de exaustão de veículos automotores (especialmente os movidos a diesel), na fumaça do cigarro e da madeira, além de alimentos grelhados na brasa. Ele é capaz de ser metabolizado pelo citocromo P450 e seu metabólito interage com o DNA, sendo então mutagênico e altamente carcinogênico. Os principais resultados mostram que o DBahA se difunde para o interior dos modelos e forma aglomerados. Quando o DBahA está em concentração elevada na parte exterior dos modelos, este não consegue se difundir facilmente para o interior dos modelos na escala de tempo simulado e forma aglomerados na interface água/modelo. O metabólito age similarmente, no entanto prefere ficar mais próximo da cabeça polar dos modelos.

\section{Palavras-chave}

HPAs; dibenzo[a,h]antraceno; dinâmica molecular; surfactante pulmonar; membrana celular. 


\section{Abstract}

Padilla-Chavarría, Helmut Isaac; Pimentel, André Silva (Advisor). Molecular Dynamics of the Interaction of dibenz[a,h]anthracene and its Metabolite with Models of Cell Membrane and Lung Surfactant. Rio de Janeiro, 2014. 125p. Master Dissertation- Departamento de Química, Pontifícia Universidade Católica do Rio de Janeiro.

The study of the interaction of dibenz[a,h]anthracene (DBahA) and its metabolite with cell membrane and pulmonary surfactant models was performed by molecular dynamics. The cell membrane and pulmonary surfactant models usually are mixtures of dipalmitoyl phosphatidylcholine (DPPC), dipalmitoyl phosphatidylglycerol (DPPG), and cholesterol. In the case of pulmonary surfactant, the models may include surfactant proteins (SP-A, SP-B, SP-C and SP-D). In this project, the DBahA was simulated with DPPC and with a 32/32/1 mixture of DPPC/DPPG/Cholesterol. DBahA is found in automotive vehicles (especially diesel vehicles), in cigarette and wood smoke, and grilled food. The DBahA molecule is metabolized by cytochrome P450 and its metabolite interacts with DNA, being mutagenic and highly carcinogenic. The results show that the DBahA diffuses into the interior of the models forming clusters. In the simulated time scale, when the DBahA is in high concentration in the outer part of the models, it may not spread easily to the inner side of the models because it forms clusters in the water/model interface. The metabolite acts similarly, but prefers to stay closer to the polar head of the models.

\section{Keywords}

PAHs; dibenz[a,h]anthracene; molecular dynamics; pulmonary surfactant; Cell membrane. 


\section{Sumário}

1 Introdução 16

1.1. Introdução 16

2 Hidrocarbonetos Policíclicos Aromáticos (HPAs) 18

2.1. Hidrocarbonetos Policíclicos Aromáticos (HPAs) 18

2.1.1. Citocromos 20

2.1.2. Propriedades comuns dos HPAs carcinogênicos 23

2.1.3. HPAs no Pulmão 25

2.1.4. HPAs na membrana celular e no surfactante pulmonar 26

2.2. Modelos de membrana celular e de Surfactante Pulmonar 27

2.2.1. Interfaces 27

2.2.2. Tensioativos 30

2.2.3. Membranas 34

2.2.4. Permeabilidade 36

2.2.5. Surfactante Pulmonar 36

2.2.6. Simulação de Modelos de Membrana Celular e de Surfactante

Pulmonar. $\quad 39$

3 Fundamentação Teórica 41

3.1. Dinâmica Molecular 41

3.1.1. Dinâmica Molecular Clássica 41

3.2. Campos de Força da Dinâmica Molecular Clássica 42

3.2.1. Interações entre átomos ligados 43

3.2.2. Interações entre átomos não ligados 44

3.3. Algoritmos da dinâmica molecular 46

3.3.1. Algoritmo Verlet 48

3.3.2. Algoritmo Leap-Frog 49

3.3.3. Algoritmo de velocidade de Verlet 49

3.4. Algoritmos de Minimização de Energia 50

3.5. Ensembles $\quad 51$

3.5.1. NVT 52

3.5.2. NPT 52 
3.6. Termostatos 53

3.6.1. Termostato de redimensionamento 53

3.6.2. Termostato Berendsen $\quad 54$

3.6.3. Termostato Nosé-Hoover 54

3.7. Barostatos 55

3.7.1. Barostato Berendsen $\quad 55$

3.7.2. Barostato Nosé-Hoover 56

3.8. Modelos de água 56

3.9. Campos de Força Gromos e Gromos53A6 58

3.9.1. Interações 60

3.9.2. Interações entre átomos ligados $\quad 61$

3.9.3. Interações entre átomos não ligados 61

3.10. PME 63

3.11. LINCS 64

3.12. Gromacs 65

$\begin{array}{ll}4 \text { Objetivos } & 67\end{array}$

5 Metodologia $\quad 68$

5.1. Resumo da metodologia. 68

5.2. Parâmetros 68

5.3. Formação dos sistemas. $\quad 69$

5.3.1. Modelo de DPPC com DBahA e metabólito inicialmente na fase aquosa. $\quad 69$

5.3.2. Modelos de DPPC e DPPC/DPPG/Colesterol DBahA e metabólito inicialmente na fase lipídica.

5.4. Etapa de minimização de energia 72

5.4.1. Modelo de DPPC com DBahA e metabólito inicialmente na fase aquosa. $\quad 74$

5.4.2. Modelos de DPPC e DPPC/DPPG/Colesterol DBahA e metabólito inicialmente na fase lipídica. 75

5.5. Dinâmica Molecular 75

6 Resultados e Discussões $\quad 79$

6.1. Verificação e Validação 79

6.1.1. Temperatura 80

6.1.2. Pressão 80 
6.1.3. Energia $\quad 81$

6.1.4. Função de distribuição radial 82

6.1.5. Área superficial xy, Área por fosfolipídio. 89

6.2. Comportamento e influência do dibenzo[a,h]antraceno e de seu metabólito 90

6.2.1. Preferência de fase 90

6.2.2. Orientação 95

6.2.3. Gráfico de densidades 96

$\begin{array}{ll}\text { 6.2.4. Perfil de densidade eletrônica } & 97\end{array}$

6.2.5. Espessura da bicamada fosfolipídica 98

6.2.6. Parâmetro de ordem 103

$\begin{array}{ll}\text { 6.2.7. Difusão xy } & 107\end{array}$

6.2.8. Difusão na normal 110

6.2.9. Formação de agregados 113

6.3. Resumo de Resultados 118

7 Conclusões 119

8 Referência Bibliográfica $\quad 121$ 


\section{Lista de figuras}

Figura 1-1 Esquema das etapas de formação do metabólito. 20

Figura 1-2 Esquema etapas de metabolização do BAP. 22

Figura 5-1 Temperatura dos sistemas simulados. $\quad 80$

Figura 5-2 Pressão dos sistemas simulados. $\quad 81$

Figura 5-3 Energia total dos sistemas simulados. 82

Figura 5-4 Função de distribuição radial, átomos de nitrogênio e

fósforo (N-P), modelo DPPC. 84

Figura 5-5 Função de distribuição radial, átomos de fósforos (P-P),

modelo DPPC. $\quad 85$

Figura 5-6 Funções de distribuição radial, centros de massa sn-1

e sn2, modelo DPPC. 86

Figura 5-7 Função de distribuição radial, átomos de nitrogênio e fósforo (N-P), modelo DPPC/DPPG/Colesterol. $\quad 87$

Figura 5-8 Função de distribuição radial, átomos de fósforos (P-P), modelo DPPC/DPPG/Colesterol. $\quad 88$

Figura 5-9 Funções de distribuição radial, centros de massa sn-1 e sn-2, modelo DPPC/DPPG/Colesterol. 89

Figura 5-10 Trajetórias centro de massa, fósforo e cada molécula de DBahA e seu metabólito, inicialmete na fase aquosa, modelo DPPC.

Figura 5-11 Trajetórias centro de massa, fósforo e cada molécula de DBahA e seu metabólito, inicialmete na fase lipídica, modelo DPPC.

Figura 5-12 Trajetórias centro de massa, fósforo e cada molécula de DBahA e seu metabólito, inicialmete na fase lipídica, modelo DPPC/DPPG/Colesterol.

Figura 5-13 Sistemas inciais e finais, inicialmente na fase aquosa, modelo DPPC. 96

Figura 5-14 Densidade eletrônica em função da possição Z. 98

Figura 5-15 Espessura da bicamada, modelo DPPC. 99

Figura 5-16 Espessura da bicamada, modelo

DPPC/DPPG/Colesterol. 100

Figura 5-17 Densidade em função do eixo Z dos átomos de fósforo. 101

Figura 5-18 Desvio padrão do gráfico de densidade dos átomos de fósforo. 
Figura 5-20 Quadrado do deslocamento médio lateral, modelo DPPC.

Figura 5-21 Quadrado do deslocamento médio lateral, modelo

DPPC/DPPG/Colesterol.

Figura 5-22 Quadrado do deslocamento médio na normal, modelo DPPC.

Figura 5-23 Quadrado do deslocamento médio na normal, modelo DPPCDPPG/Colesterol.

Figura 5-24 Coeficientes de difusão no eixo Z.

Figura 5-25 Sistemas inciais e finais, inicialmente na fase lilpídica, modelo DPPC.

Figura 5-26 Sistemas inciais e Finais, inicialmente na fase aquosa, modelo DPPC/DPPG/Colesterol. 


\section{Lista de tabelas}

Tabela 5-1 Coeficientes de difusão dos fosfolipídios nos modelos de DPPC e de DPPC/DPPG/Colesterol.

Tabela 5-2 Área do sistema $\left(\mathrm{nm}^{2}\right)$, Área por Fosfolípidio $\left(\mathrm{nm}^{2}\right)$ e área por molécula $\left(\mathrm{nm}^{2}\right)$ nos sistemas com DPPC e DBahA e fosfolipídio inicialmente na fase lipídica.

Tabela 5-3 Espessuras (em nm) para cada sistema de DPPC com o DBahA e do mDBahA na fase lipídica, calculadas com os últimos 30 ns de simulação.

Tabela 5-4 Valores do parâmetro de ordem para a cauda 1 (sn1) dos sistemas de DPPC com DBahA e mDBahA inicialmente na fase lipídica.

Tabela 5-5 Valores do parâmetro de ordem para a cauda 2 (sn2) dos sistemas de DPPC com o DBahA e mDBahA inicialmente na fase lipídica.

Tabela 5-6 Valores do parâmetro de ordem para a cauda 1 (sn1) dos sistemas de DPPC/DPPG/Colesterol.

Tabela 5-7 Valores do parâmetro de ordem para a cauda 2 (sn2) dos sistemas com DPPC/DPPG/Colesterol.

Tabela 5-8 Coeficientes de difusão no eixo z para DBahA e seu metabólito nas bicamadas fosfolipídicas de DPPC e de DPPC/DPPG/ Colesterol.

Tabela 5-9 Coeficientes de difusão no eixo z para dibenzo[a,h]antraceno e seu metabólito nas bicamadas fosfolipídicas de DPPC e de DPPC/DPPG/Colesterol.

Tabela 5-10 Resumo de resultados das simulações com o DBahA e seu metabólito inicialmente na fase lipídica. 


\section{Lista de ilustrações}

Ilustração 1 Possiveis mesofases formadas por surfactantes.

Adaptado de Myers(MYERS, 2005).

Ilustração 2 Componentes da membrana biológica. Adaptado de

Koolman e Röhm(KOOLMAN; RÖHM, 2005).

Ilustração 3 Estruturas formadas pelo surfactante pulmonar e pelas proteinas asociadas. Adaptado de Pérez-Gil(PÉREZ-GIL, 2008).

Ilustração 4 Bicamada de DPPC previamente equilibrada.

llustração 5 Foto instantânea que mostra exemplos dos agregados formados na simulação com 40 moléculas de DBahA na bicamada fosfolipídica de DPPC. São mostradas apenas as moléculas de DBahA, onde é aplicada sobre elas uma representação com o raio de van der Walls e a superfície acessível ao solvente. 


\section{Lista de quadros}

Quadro 1 HPAs e atividade carcinogênica

Quadro 2 HPAs considerados como possíveis carcinogênicos

segundo segundo agências.

Quadro 3 Partição de HPAs entre o material particulado e a fase

gasosa.

Quadro 4 Estruturas formadas segundo forma crítica de empacotamento e valores do parâmetro crítico de empacotamento.

Quadro 5 Composição de surfactante natural e sintético.

Quadro 6 Estruturas das moléculas usadas nas simulações com

as fontes da topologia.

Quadro 7 Estruturas iniciais do modelo de DPPC com DBahA e mDBahA inicialmente na fase aquosa. Em vermelho os átomos de nitrogênio e fósforo delimitando a membranas, em azul a fase aquosa e em amarelo os HPAs.

Quadro 8 Estruturas iniciais do modelo de Modelos de DPPC com DBahA e mDBahA inicialmente na fase lipídica.

Quadro 9 Parâmetros importantes da etapa de minimização de energia.

Quadro 10 Parâmetros importantes da etapa de equilíbrio, inicialmente na fase aquosa.

Quadro 11 Parâmetros importantes da etapa de equilíbrio, inicialmente na fase lipídica.

Quadro 12 Parâmetros importantes da etapa de dinâmica molcular. $\quad 77$

Quadro 13 Características iniciais dos sistemas simulados. 